\title{
Understanding Australian policies on public health using social and political science theories: reflections from an Academy of the Social Sciences in Australia Workshop
}

\author{
Fran Baum ${ }^{1}$, Adam Graycar ${ }^{2}$, Toni Delany-Crowe ${ }^{1, *}$, Evelyne de Leeuw ${ }^{3}$, \\ Carol Bacchi ${ }^{4}$, Jennie Popay ${ }^{5}$, Lionel Orchard ${ }^{6}$, Hal Colebatch ${ }^{7}$, \\ Sharon Friel ${ }^{8}$, Colin MacDougall $^{9}$, Elizabeth Harris ${ }^{10}$, Angela Lawless ${ }^{11}$, \\ Dennis McDermott ${ }^{12}$, Matthew Fisher ${ }^{1}$, Patrick Harris ${ }^{13}$, Clare Phillips ${ }^{1}$, \\ and Jane Fitzgerald ${ }^{1}$
}

1Southgate Institute for Health, Society and Equity, Flinders University, Adelaide, SA 5001, Australia, ${ }^{2}$ College of Business, Government and Law, Flinders University, Adelaide, SA 5001, Australia, ${ }^{3}$ Centre for Health Equity, Training, Research and Evaluation, University of New South Wales, Sydney, NSW 2052, Australia, ${ }^{4}$ Politics and International Studies, University of Adelaide, Adelaide, SA 5005, Australia, ${ }^{5}$ Centre for Health Inequalities, Lancaster University, Lancaster, LA1 4YW, UK, ${ }^{6}$ Formerly Politics and Public Policy, Flinders University, Adelaide, SA 5001, Australia, ${ }^{7}$ School of Social Sciences, University of Adelaide, Adelaide, SA 5005, Australia, ${ }^{8}$ School of Regulation and Global Governance, Australian National University, Canberra, ACT 2601, Australia, ${ }^{9}$ College of Medicine and Public Health, Flinders University, Adelaide, SA 5001, Australia, ${ }^{10}$ Centre for Primary Health Care and Equity, University of New South Wales, Sydney, NSW 2052, Australia, ${ }^{11}$ College of Nursing and Health Sciences, Flinders University, Adelaide, SA 5001, Australia, ${ }^{12}$ Poche Centre for Indigenous Health and Well-being, Flinders University, Adelaide, SA 5001, Australia and ${ }^{13}$ Menzies Centre for Health Policy School of Public Health, University of Sydney, Sydney, NSW 2006, Australia

*Corresponding author. E-mail: toni.delanycrowe@flinders.edu.au

\section{Summary}

There is strong, and growing, evidence documenting health inequities across the world. However, most governments do not prioritize policies to encourage action on the social determinants of health and health equity. Furthermore, despite evidence concerning the benefits of joined-up, intersectoral policy to promote health and health equity, it is rare for such policy approaches to be applied systematically. To examine the usefulness of political and social science theory in understanding the reasons for this disjuncture between evidence and practice, researchers and public servants gathered in Adelaide for an Academy of the Social Sciences in Australia (ASSA) Workshop. This paper draws 
together the learnings that emerged from the Workshop, including key messages about the usefulness of various theories as well as insights drawn from policy practice. Discussions during the Workshop highlighted that applying multiple theories is particularly helpful in directing attention to, and understanding, the influence of all stages of the policy process; from the construction and framing of policy problems, to the implementation of policy and evaluation of outcomes, including those outcomes that may be unintended. In addition, the Workshop emphasized the value of collaborations among public health researchers, political and social scientists and public servants to open up critical discussion about the intersections between theory, research evidence and practice. Such critique is vital to render visible the processes through which particular sources of knowledge may be privileged over others and to examine how political and bureaucratic environments shape policy proposals and implementation action.

Key words: Determinants of health, evidence based policy, healthy public policy, politics

\section{INTRODUCTION}

There is strong evidence documenting health inequities gradients globally. Persistent health inequities have led to repeated calls for innovative policy approaches that promote health and wellbeing through action on the social and economic determinants of health, to create conditions that are conducive to improved population health, wellbeing and equity (WHO Task Force on Research Priorities for Equity in Health and The WHO Equity Team, 2005; Baum, 2008; CSDH, 2008). The World Health Organisation has promoted a focus on the social determinants of health (SDH) and health equity including through the global Commission on the Social Determinants of Health (CSDH, 2008) and the Rio Political declaration (WHO, 2011). Despite recommendations from this Commission and a range of subsequent national and regional reports on the same topic (World Health Organization, 1986; WHO, 1997; CSDH, 2008; Marmot et al., 2008), evidence indicates that most governments, including governments in Australia, do not prioritize policies to encourage action on $\mathrm{SDH}$ and health equity (Exworthy et al., 2003; Povlsen et al., 2014). Government policy has been slow to move away from a focus on individual behaviours in determining health outcomes, and interventions that target the SDH still tend to be downplayed (Fisher et al., 2016).

The European Union and the World Health Organisation have advocated for, and facilitated, intersectoral action on the SDH through promotion of 'Health in All Policies' (HiAP) approaches. HiAP provides a model for sectors of government to work collaboratively on policy issues of mutual concern in ways that will promote health, wellbeing and equity, while mediating between sectoral interests (Ståhl et al., 2006; World Health Organisation, 2010). HiAP is underpinned by the idea that all sectors of government influence population health, wellbeing and equity, and that some of the strongest influences lie outside the health sector. HiAP builds upon a long history of theory and conceptual development in the health promotion movement, including the concepts of intersectoral action for health, and healthy public policy (World Health Organization, 1978, 1986). Despite this long history, it is rare for intersectoral policy approaches to be applied systematically to address SDH.

Furthermore, it is rare for theoretical insights to be applied to develop understanding about how to increase support for, and the effectiveness of, policy work to address the SDH (de Leeuw et al., 2014a). For example, the extensive political science knowledge about policy processes is seldom applied to the study of healthy public policy (Breton and de Leeuw, 2011). In their review of the barriers to SDH issues reaching government policy agendas, Embrett and Randall (2014, p. 154) concluded that unless this knowledge were applied more systematically there was unlikely to be an increase in the adoption of healthy public policies.

Funding support was sought by Flinders University from the Academy of the Social Sciences in Australia (ASSA) to explore this discourse arena. The purpose of the ASSA workshop was to improve understanding about how the application of social and political science theory could further illuminate the study of healthy public policy.

\section{WORKSHOP DETAILS}

The invitation-only Workshop was attended by 22 people, including leading international policy analysts from the social and political sciences, public servants from South Australia, New South Wales and Tasmania and several early career researchers. The aims of the Workshop were to: 
- Develop theoretical understandings of why disease prevention and health promotion have a marginal position on the political and policy agenda despite their importance in shaping population health.

- Stimulate in-depth discussion to identify key insights from political science and social theory into factors that shape the implementation of complex policy initiatives aiming to improve health and wellbeing equitably through action on the SDH.

- Apply these insights to practical examples of policy implementation to develop improved theoretical understanding of the processes of developing and implementing disease prevention and health promotion policy.

Sixteen academics from Australia and the United Kingdom presented papers, drawing on various theoretical frameworks and concepts. Eleven of these academics and four of the public servants acted as discussants, extending and challenging the ideas offered by the presenters during each session. The Workshop was organized into eight sessions across 2 days. The Workshop structure was intended to provide opportunities for theoretical reflection as well as sharing of understandings derived from policy practice and theory-driven analysis of particular settings, health issues and populations.

\section{CONCEPTUAL LEARNING}

During the Workshop Kingdon's multiple streams approach (Kingdon, 2011) was drawn on most frequently, and several references were made to traditional conceptions of policy stages and cycles (Howlett et al., 1995). Both of these approaches were considered somewhat useful in understanding how the SDH are dealt with and/or marginalized. However, the Workshop presenters and participants generally rejected linear models of policy, and instead highlighted the turbulence of agenda setting, policy development and the influences of power and ideology—all of which add complexity to policy (de Leeuw et al., 2016; Howlett et al., 2016). The presenters also considered the real world implementation of policy, rendering an isolated focus on Kingdon's agenda setting model insufficient. Through discussion, the Workshop participants grappled with the variability in policy processes, sectoral approaches and political systems; realizing that lessons derived from one policy arena were not necessarily applicable to all. It was within this context that the power of combining multiple theoretical approaches was realized. It was also recognized that combining theory with wisdom drawn from policy practice was particularly fruitful in understanding the complexity and ambiguity of policy processes.
Table 1 presents the multiple theories and concepts that were discussed during the Workshop, and aligns these with relevant aspects of policy development, implementation and evaluation processes. The key messages resulting from the application of these theories and concepts during the Workshop, along with insights from policy practice, are then explained.

\section{Framing the 'problem' and establishing the policy agenda}

During the Workshop several presenters focused on examining the forces that construct particular issues as policy priorities.

Carol Bacchi presented a post-structural analytical framework called What's the Problem Represented to $B e$ ? [see (Bacchi, 1999, 2009, 2016)]. The framework introduces seven interrelated forms of questioning that interrogate how policies and policy proposals frame the issues that they purport to address in particular ways. Through applying this approach Bacchi identified the individualist premises that permeate some policies that are intended to target the social determinants of healthy behaviours (Bacchi, 2016). Bacchi argued that a focus on the causes of individual behaviours, rather than broader social forces and structures of power, may inadvertently bolster a focus on lifestyles as opposed to the SDH (Bacchi, 2016). Bacchi's approach draws on governmentality theory to render visible, and problematize, the deep-seated presuppositions and assumptions that underpin policy proposals, to understand what they encompass, what they leave out and who is harmed as a result. Responses from the public servants who participated in the Workshop indicated that Bacchi's approach is useful to them in illuminating the unspoken processes through which issues become framed (or not) as policy problems. They also stressed the strong influence of political acceptability (i.e. alignment with the values, ideologies and norms preferred by the governing party) (Steg et al., 2011) in determining which ideas are taken up, regardless of the associated evidence.

Evelyne de Leeuw demonstrated the value of bringing together several theories of policy process to understand the multiple forces shaping policy agendas [see (de Leeuw et al., 2013, 2014a)]. de Leeuw focussed on a 'Realist Synthesis' approach to policy analysis, which employs Kingdon's agenda setting (three streams) model (Kingdon, 2011) in conjunction with policy network theory, network management perspectives and stakeholder analyses. Using this hybridized approach assists in overcoming some of the problems associated with agenda setting frameworks, which are difficult to use as 
Table 1: Theories and concepts applied during the Workshop to understand why SDH occupies a marginal position on the policy agenda

\begin{tabular}{|c|c|}
\hline $\begin{array}{l}\text { Aspect of policy development and } \\
\text { implementation processes }\end{array}$ & Useful theories, concepts and approaches \\
\hline $\begin{array}{l}\text { Framing the 'problem' and } \\
\text { establishing the policy agenda }\end{array}$ & $\begin{array}{l}\text { - 'What's the Problem Represented to Be?' Approach (Bacchi, 1999, 2009) } \\
\text { - 'Realist Synthesis' approach (hybridization of Kingdon's agenda setting } \\
\text { model, policy network theory, network management perspectives and } \\
\text { stakeholder analyses) (de Leeuw et al., 2014a) } \\
\text { - Agenda setting model (Kingdon, 2011) } \\
\text { - Norm life cycle framework (Finnemore and Sikkink, 1998) } \\
\text { - ACF (Jenkins-Smith } \text { et al., 2014) } \\
\text { - PET (Baumgartner, 2013; Baumgartner et al., 2014) } \\
\text { - Trade liberalization (Friel et al., 2013) }\end{array}$ \\
\hline $\begin{array}{l}\text { Ideological influences on } \\
\text { decision making }\end{array}$ & $\begin{array}{l}\text { - Critique of neoliberalism (Miller and Orchard, 2014) } \\
\text { - 'Special treatment' approach (Pedersen and Barlow, 2008) } \\
\text { - Spectrum of Response Framework (Sjoberg and McDermott, 2016) }\end{array}$ \\
\hline Policy formulation & $\begin{array}{l}\text { - Official problem-solving perspective (Colebatch, 2005) } \\
\text { - Collective management of the problematic perspective (Colebatch, 2005) } \\
\text { - Multiple constructions of children approach (MacDougall and Darbyshire, 2017) } \\
\text { - Agenda setting model (Kingdon, 2011) } \\
\text { - Lifestyle drift (Hunter et al., 2010) }\end{array}$ \\
\hline Policy implementation & $\begin{array}{l}\text { - Equity drift } \\
\text { - Lifestyle drift (Hunter et al., 2010) } \\
\text { - Policy myopia (Bacigalupe et al., 2010) }\end{array}$ \\
\hline Monitoring and evaluation of policy & $\begin{array}{l}\text { - Rapid review [see, e.g. (Osborne et al., 2013)] } \\
\text { - Program theory and action research (Weiss, 2000; Astbury and Leeuw, 2010) }\end{array}$ \\
\hline
\end{tabular}

a basis for speculating about the likely success of a policy initiative following implementation since the main focus is on understanding, retrospectively, how an idea enters the policy agenda. Fully operationalizing a Kingdon agenda setting approach (Kingdon, 2011), along with other theories of political process, directs attention to the dynamic interactions that occur between policy problems, proposed solutions and political will, and to the dynamics of power that flow through particular policy network configurations. Power serves to mobilize particular issues and interests on the policy agenda while supressing others (de Leeuw et al., 2014b, 2015).

Fran Baum continued the discussion of how particular issues achieve prominence on the policy agenda, by presenting another hybridized analysis of the factors that led to the implementation of a HiAP approach in South Australia (SA) (Government of South Australia, 2010). Baum applied Kingdon's agenda setting model (Kingdon, 2011) to argue that it was evident that the problem stream (high healthcare costs, perceived need for improved cross-sector action), the policy stream (considerable expertise in social determinants policy within some sectors of the Government and a Thinker in Residence scheme) and the political stream (stable government with a reform agenda, bi-partisan support for HiAP and a strategic plan) converged to open a window for implementation (Baum et al., 2014, 2015). Baum drew on the norm life cycle framework (Finnemore and Sikkink, 1998) to explain that, together, these factors caused a norm cascade that has seen HiAP established as an acknowledged, valued and accepted part of the South Australian policy environment (Baum et al., 2015). Baum also emphasized the importance of context by identifying several crucial factors that increased acceptance of HiAP. These included a history of concern for social justice and intersectoral action in the State, the existence of effective policy entrepreneurs, a positioning of HiAP as a possible solution to the perceived healthcare budget crisis and a cadre of public servants with the skills to implement the initiative.

Patrick Harris combined Kingdon's multiple streams approach (Kingdon, 2011), the advocacy coalition framework (ACF) (Jenkins-Smith et al., 2014), and punctuated equilibrium theory (PET) (Baumgartner, 2013; Baumgartner et al., 2014) to a case study of urban 
planning and health. Harris explained the mechanisms and conditions that led to the inclusion of health within 2 of the 11 draft legislative objectives that guided comprehensive reforms of the land use planning system in New South Wales (NSW), Australia (Harris et al., 2015, 2016, 2017). Harris' analysis revealed the foundations of policy-making as complex, incremental and nonlinear, characterized by long periods of stasis with the emergence of seemingly sudden, and often time-limited, opportunities for change (Baumgartner and Jones, 1993; Baumgartner et al., 2014). Harris explained that the perspectives provided by each theory differed subtly, but all theories emphasized the role of the actors and ideas operating within core institutional boundaries. The multiple streams approach (Kingdon, 2011) explained that change occurred because 'healthy planning' entrepreneurs, who had been collaborating for over a decade, took the reforms (the problem stream) to create a window of opportunity. They presented a clear 'healthy planning objective' that became accepted by government (the policy stream) and developed support amongst the majority of stakeholders (the politics stream). The ACF (Jenkins-Smith et al., 2014) showed that health was well positioned due to different actors' common commitment to a health objective, despite differing beliefs and positions about other core issues. PET (Baumgartner, 2013; Baumgartner et al., 2014) suggested that the principle mechanism for change was the purposeful and consistent framing of a clear healthy planning objective, allowing it to become an accepted and salient idea over time.

Sharon Friel focussed on examining the influence of ideology, actors and interests in shaping the policy agenda through a case study of the development of the Trans-Pacific Partnership (TPP) agreement. Friel used the concept of trade liberalization to explain how removing barriers to trade can significantly influence the distribution of power, money and resources between and within countries. This, in turn, affects people's daily living conditions and the local availability, quality, affordability and desirability of products (e.g. quality and affordable food, tobacco, alcohol, medicines and accessible health care). Friel reflected on the political and monetary power of the stakeholders involved in trade agreements, and highlighted the vested interests as barriers to any consideration of the SDH through a privileging of other imperatives, especially financial gain, during negotiations. She also stressed the value of advocacy from community members and organized groups in creating opposing political pressure.

Jane Fitzgerald interrogated the importance of policy framings by applying Bacchi's What's the Problem Represented to Be approach (Bacchi, 2009, 2016) with
Kingdon's agenda setting (Kingdon, 2011) framework to illuminate policy silences in mental health policy. Fitzgerald's research involves critical examination of policies in three sectors of the South Australian Government-Health, Environment and Urban Planning-to determine how mental health and wellbeing are represented, or silenced, within the policies and actions of those departments. Fitzgerald reflected on the relevance of the built and green environments to promoting psychological wellbeing, yet explained the tendency for 'mental health' policy to overlook the impact of the broader environments on psychological wellbeing and population mental health and to focus instead on the individualized treatment of mental illness.

\section{Ideological influences on decision making}

A key theme that emerged during the Workshop related to the importance of understanding how political ideologies shape policy contexts. Drawing on his work with Chris Miller [see (Miller and Orchard, 2014)], Lionel Orchard applied a critique of neoliberalism to argue that public policy in Australia reflects neoliberal values that often conflict with social democratic values, such as equity and social justice. Thus since the 1980s Australian politics has been dominated by efforts to achieve an open, competitive economy through financial deregulation and privatization, while limiting the size of government and reducing taxation. Attempts to shift dramatically in either conservative or neoliberal directions have proved difficult for all Australian governments since that time. Through his critique [see (Miller and Orchard, 2014) for further detail], Orchard argued that neoliberalism has had a corrosive impact on Australian welfare policy, prioritizing the responsibilities of the individual within a complex redistributive framework. Such a focus is largely inadequate to tackle the deep roots of social inequity.

Continuing a similar focus to Orchard, Jennie Popay provided an overview of the United Kingdom's (UK) policy environment, and focussed on the evident growing inequities in income and health outcomes. Popay argued that transformation of the local and national state has intensified due to the explicit aspiration of the UK Government to be a state that spends less but delivers more. The transformation sees a further privatization of public assets, and intensification of the marketization of health, social care and education. Popay explained that UK policies to address social inequities rely predominately on an individual empowerment model, which is insufficient to address the structural causes of disadvantage. 
Dennis McDermott continued examining the influence of ideology in shaping decision making and restricting potential for action. He presented a detailed analysis of the process and outcomes of an intersectoral policy formation project intended to improve Aboriginal road safety through increasing the number of Aboriginal people who could attain and retain their driver licenses. He tracked the process through which the scope and interdepartmental reach of the project recommendations were reduced considerably. McDermott argued that the 'pruning' of the recommendations, ostensibly for the purposes of achieving political acceptability, restricted the value of the policy outcome. The pruning reflected strong resistance to systems changes which were interpreted by some as potentially resulting in the 'special treatment' of Indigenous Australians (Pedersen and Barlow, 2008). McDermott analysed this resistance by applying the Spectrum of Response Framework (Sjoberg and McDermott, 2016) and identified it as resulting from unfamiliarity, discomfort and racism. He presented this case study as evidence of how a broad, inclusive focus on the SDH of Indigenous Australians' health is politically untenable.

\section{Policy formulation}

Hal Colebatch applied two different explanations of how policies are formed and governed: (i) official problem-solving operationalized by governments and (ii) the policy process as the collective management of the problematic [see (Colebatch, 2010)]. Within the first framing, policy development is understood as occurring through the actions of individuals within government who recognize problems, choose instruments to deal with them, and then direct subordinates within or outside of government to give effect to these choices. When the chosen strategies are not operationalized, or the desired effect is not achieved, 'implementation failure' is considered to have occurred, and this is addressed with efforts to develop better plans, gain more resources or attract more 'political will'.

The second explanation proposes that there are many more participants involved than those who work within government, and that all those involved have distinct agendas. Much of the activity is 'collective puzzling' (Colebatch, 2010) about the nature of the problem, and appropriate responses. This puzzling is shaped by historical experience and institutional frameworks. Policy is what emerges from this process, not something that was determined at the beginning or as something that necessarily addresses a pre-defined problem. Rather, policies are considered as embryos, shaped by the influences brought to bear upon them (Pressman and Wildavsky, 1984).

Colebatch illustrated these perspectives on policy through the case of the development of smoking policy in Australia. In the first account, smoking policy is understood as a planned, comprehensive set of policies initiated by the Federal government, coordinated with the States, to work on a clearly defined problem, resulting in a change in behaviours and a fall in smoking and smoking-related disease-i.e. a 'policy success'. The second explanation posits that there were many actors involved, with wide divergence on what the problem was and what should be done about it, with governments reluctant to act, and the initiative for smoking reductions being driven largely from outside government (e.g. lobby groups). Applying the second explanation allows for a broader view of 'the problem' that smoking policy was introduced to address, particularly given that smoking rates had been falling before any policy measures to reduce them were introduced by governments. This leads to the interpretation of smoking policy initiatives as reflective of a change in social practice, rather than the sole cause of it.

Colin MacDougall focussed on theories about, and representations of, childhood in shaping policy formulation [see (MacDougall and Darbyshire, 2017)]. He identified the following representations of children, which in political science terms refers to how children are framed within policy: (i) the 'economic child', whereby children are framed as consumers in systems that are designed and implemented by adults, often using free market principles, (ii) 'developing beings', which draws on psychology and stages of human development, with the end result of education and intervention being well-adjusted adults, (iii) 'children as citizens', which focuses policy on children's rights and sees children as citizens in the making, who are capable of, and have the right to, contribute to research, policy and other decisions that shape their lives and (iv) the 'global child perspective', which argues that poverty, climate change and war are globally determined and that children have the right to be involved in efforts to address these issues because they will be affected by them. Through presenting findings from a policy analysis, MacDougall argued that Australian policies on physical activity commonly use the economic and developmental child perspectives. Policy on physical activity still most commonly centers on actions that emphasize individual responsibility, either of children themselves or of their parents where adults take the role of duty bearers in regard to children's welfare. This downplays the influence of social and economic 
factors in influencing individual behaviours, and represents a 'lifestyle drift' within the policies.

Clare Phillips continued the focus on children, drawing on Kingdon's agenda setting approach (Kingdon, 2011) to examine the factors that facilitate a focus on social determinants within child and youth health policy. Phillips explained that the three streams (Kingdon, 2011) converged to open a window of opportunity for a $\mathrm{SDH}$ approach in the development of four specific Australian child health policies between 2008 and 2011. The factors that facilitated this were bipartisan political support, a political desire to promote children's health, political consensus at Federal and State/Territory levels, experienced policy entrepreneurs with a deep understanding of the relevance of social determinants working through diverse policy networks, independent Institutions/Commissioners who pursued a SDH agenda and effective consultations with children and youth during policy development.

Matthew Fisher applied the concept of 'lifestyle drift' to analyse policy formulation [see (Fisher et al., 2017)]. Fisher summarized findings from an analysis of 266 Australian health policy documents to show that lifestyle drift was present in around a third of these policies. This drift meant while Australian Governments articulated a commitment to addressing the wider SDH they actually propose narrow interventions to change individual attributes or behaviours (Hunter et al., 2010). Fisher reinforced this interpretation through their analysis of how lifestyle and equity drift occurs during policy implementation to shift the focus from the social environment to the biological, psychological or behavioural attributes of individuals.

\section{Policy implementation}

Jennie Popay argued that lifestyle drift is a crucial factor that stifles action on the SDH in the UK (Hunter et al., 2010; Popay et al., 2010). Popay examined the multiple, complex and highly political problems that contribute to lifestyle drift. First, broad ideological and structural changes are required to ensure that addressing the SDH is considered feasible and acceptable. For example, recognition that redistribution of wealth to create a fairer society will have flow-on benefits for all citizens is still not widespread (and in fact disputed by the current dominant economic models). Thus, current political thinking does not provide the conditions necessary to open windows of opportunity. The required changes are unlikely to emerge from political landscapes dominated by neoliberal ideologies (Townsend, 2009; Grimshaw and Rubery, 2014). Second, research-informed ideas that do not align with political priorities may be easily disregarded, particularly if they do not conform to what is traditionally regarded as strong research evidence (e.g. randomized controlled trials) which, in turn, reinforces medicalized constructions of reliable knowledge. This limits the ability of SDH research to survive on the policy agenda and limits the extent to which public health research methods are considered credible (Smith, 2013). Third, public health activists have failed to appreciate the profound political dimensions of a SDH approach. Greater connectedness and commitment from civil society and public engagement is required to advance the SDH agenda (de Leeuw and Clavier, 2011). Popay drew on the work of Katherine Smith to argue that (Smith, 2013) the tendency for researchers to focus on behaviours is motivated by the greater uptake of behavioural research findings in policy circles, thereby increasing researchers' perceptions of impact, their likelihood of future funding and the credit from academic institutions.

Elizabeth Harris noted that equity drift is similar to lifestyle drift but it more specifically describes the process through which governments start with a commitment to access and equity as a core value but then are unable to either define equity, make explicit what they hope to achieve through, or articulate what the actions to promote equity would look like (see Supplementary Material). Harris argued that equity drift has operated in NSW health policy as a result of deep-seated institutional norms and values which conflict with equity. She also explained that technical aspects related to evidence on equity make an equity agenda difficult to prosecute, including difficulties in measuring improvements in equity and a lack of associated predictive power. While these issues can be overcome, the political impetus to do so can be lacking when decisions are often made on the basis of aspirations for power, and a need for immediate results, rather than a drive for fairness.

Building on the work presented by Baum, Toni Delany-Crowe explained the factors that had facilitated and impeded implementation of the HiAP approach in South Australia [see (Delany et al., 2015)]. DelanyCrowe explained that intersectoral work to promote health, particularly by addressing SDH and health equity, is frustrated by a politically driven, narrow focus on strategies that will achieve short-term results-a form of 'policy myopia' (Bacigalupe et al., 2010), where politicians divert resources into policies that will yield results in their term in office. This results from short electoral terms, and the dominant concern with maintaining power, which is often not perceived as compatible with long-term social change (Bacigalupe et al., 2010; Greaves and Bialystok, 2011; Ollila, 2011). 
Delany-Crowe explained that siloed structures of accountability, where ministers are held accountable only for sector-based achievements, deters the intersectoral collaboration that is imperative to address the $\mathrm{SDH}$ through policy action.

\section{Monitoring and evaluation of policy}

Baum then examined the Closing the Gap (CTG) initiative, questioning whether the health, equity and life expectancy gaps between Indigenous and non-Indigenous Australians can be reduced without more action on the $\mathrm{SDH}$. She examined the lessons derived from a rapid review of what facilitates action on social determinants [see (Osborne et al., 2013)]. She identified crucial policies as: reducing poverty and redistributing wealth, ensuring that any social determinants approach is culturally appropriate to the needs of Aboriginal and Torres Strait Islander people, achieving cross government coordination, encouraging collaboration between government and the community sector, encouraging leadership with full commitment to CTG, taking account of the impact of colonization (especially the loss of culture and land and the ensuing legacy of trauma and grief), active engagement and employment of Aboriginal and Torres Strait Islander peoples, providing long-term funding rather than short-term pilot funding and employing strengths-based approaches. Baum argued that a dominant focus on service provision and strategies to encourage individual behaviour change within the CTG initiative will leave the structural causes of ill health and inequities in place. She also argued for improved evaluation of policy interventions to determine what works best in different contexts and which take into account the interactions among determinants.

Angela Lawless examined theory-informed policy evaluation of initiatives that are intended to stimulate action on the SDH [see (Lawless et al., 2017)]. Lawless argued that such evaluations present numerous problems because of the complex interplay of actors, institutions and ideas. Lawless explained how using a combination of program theory (Weiss, 2000; Astbury and Leeuw, 2010) and action research can assist in understanding the theory of change that underpins a policy while helping the evaluation to be relevant to fast-changing political and bureaucratic contexts. She argued that researchers need constructive negotiation with policy makers to conduct evaluative research and ideally to establish and manage partnerships between researchers and policy makers. In response, a public servant in attendance at the Workshop emphasized the difficulties associated with prospective policy research. Difficulties exist because policymaking and implementation are dynamic and complicated, and sometimes the drivers of policy decisions are not linear or clear, making it difficult to capture and describe them adequately. Sometimes ideas flow through networks in complicated ways and an initiative may not have any immediate impact but may influence policy many years later, and it is difficult for researchers to capture this. As such, research that is undertaken prospectively can miss some of the important detail and nuances. This makes regular engagement between researchers and policy makers during the research process vital. It also highlights the value of using network mapping to understand the range of actors who influence policy and show how ideas flow through networks.

\section{KEY INSIGHTS DRAWN FROM THE WORKSHOP}

The Workshop was assessed by participants as providing a rare opportunity for reflection on the role of theory in understanding the reasons why disease prevention and health promotion continue to have a marginal position on political and policy agendas. Opportunity was provided for deep discussion of politically charged, contemporary issues, which was both constructive and challenging.

\section{Intersectoral dialogue and merging of networks is valuable}

The usefulness of collaborations among researchers from public health, social and political science became apparent during the Workshop. Public health researchers offer skills in examining and theorizing the broad range of factors that influence health, while political and social scientists have rich knowledge of theories that illuminate various aspects of the policy cycle.

The co-learning was deepened by the interactions between the researchers and public servants. These encouraged joint exploration of the practical applicability of the ideas and theories being discussed, and bridged the often present divide between research and policymaking activities. One public servant in attendance commented that the Workshop had demystified the political imperatives that operate to restrict uptake of evidence during policy development, and had assisted in clarifying how research findings can be presented in ways that are likely to be more acceptable in the political context in which she works. The sharing of experience and learning during the Workshop stimulated engagement with ideas drawn from theory and practice and as such 
Table 2: Application of political and social science theory to make sense of, and critique, health promotion policy and practice

\begin{tabular}{l} 
Theory-informed sense- \\
making tool \\
\hline Critique of dominance of \\
neoliberal ideology \\
(Miller and Orchard, \\
2014) \\
Lifestyle drift (Hunter \\
et al., 2009; Popay \\
et al., 2010) \\
Policy myopia (Aidt and \\
Dutta, 2007) \\
Two key approaches for \\
understanding how the \\
acticy process, and its \\
conceptualized
\end{tabular}

1. Official problem-solving perspective

(Colebatch, 2005)

2. Collective management of the problematic perspective (Colebatch, 2005)

\section{Key premise}

Asserts that public policy in Australia reflects neoliberal values that often conflict with social democratic values, such as equity and social justice

Refers to the tendency for policy efforts to start by recognizing the need for action on upstream $\mathrm{SDH}$ and health equity and then drift downstream to a focus largely on factors related to individual lifestyle

Arises when politicians direct public money toward short-term investments that are intended to secure political power, rather than working toward long-term social benefit. The time horizons for effective policymaking are often longer than those of electoral politics, resulting in immediate political pressures overshadowing longer-term policy considerations

These two contrasting approaches draw attention to different ways of understanding the policy process. They highlight that it is important to determine how the policy process is operating and being understood. The framing of policy depends upon the perspective that is applied

The 'Official problem-solving perspective' approach posits that policy development occurs through the actions of individuals within government who recognize problems, choose instruments to deal with them and then direct subordinates within or outside of government to give effect to these choices

The 'Collective management of the problematic' approach views policymaking as a dynamic mix of actors and interests. It involves many more participants than those who work within government. It notes that all those involved have distinct agendas. Decisions are shaped by historical experience and institutional frameworks. Policy may be reflective of social change or the catalyst for it

Policies and policy proposals contain implicit representations of what is considered to be the 'problem' ('problem representations'). A What's the Problem Represented to Be?' analysis requires reading policies to discern how the 'problem' is represented within them and to subject this problem representation to critical scrutiny
Application to understand and critique health promotion policy and practice

Framework for health promoters to understand why health promotion ideas are often rejected within neoliberal regimes and provides arguments to challenge this regime. For example in relation to the impact of free trade on health (Friel et al., 2013)

Enables the analysis of how SDH perspectives in public policy can be lost when translated into specific actions that privilege behavioural and lifestyle strategies. Such strategies reflect a strong individualism and deflect attention from the structures that maintain inequities Helps health promoters understand why an emphasis on long-term benefits of health promotion often fails because of short termism in political considerations and the privileging of immediate political power rather than longterm consideration of the common good

Demonstrates that a range of actors are involved (within and outside government), providing opportunities for influence and advocacy at multiple levels. Highlights the complexity of bringing about policy change and indicates that 'collective puzzling' about the nature of the problem and solutions is vital for innovative health promotion. Stresses that these responses reflect historical experience and institutional frameworks and highlights the need for health promoters to understand these for effective policy and practice

Useful to analyse the content of policies and their application

- Targets and renders visible the assumptions that underpin the problematizations that shape policies and suggested actions

- Emphasizes the political implications of specific problem representations and the importance of identifying policy silences

- Highlights the influence of power dynamics in shaping policy 
Table 2: (Continued)

\begin{tabular}{|c|c|c|}
\hline $\begin{array}{l}\text { Theory-informed sense- } \\
\text { making tool }\end{array}$ & Key premise & $\begin{array}{l}\text { Application to understand and critique health } \\
\text { promotion policy and practice }\end{array}$ \\
\hline $\begin{array}{l}\text { Multiple streams analysis } \\
\text { (or multiple streams } \\
\text { approach) (Kingdon } \\
\text { and Thurber, 1984) }\end{array}$ & $\begin{array}{l}\text { Explains how policy agenda setting operates. The ap- } \\
\text { proach is focused on examining the problem, pol- } \\
\text { icy and political streams that operate to set } \\
\text { agendas. These remain more or less independent of } \\
\text { one another until a policy window opens, allowing } \\
\text { an issue to enter the agenda. Under certain circum- } \\
\text { stances, policy windows can be used by particular }\end{array}$ & $\begin{array}{l}\text { Directs attention to the need to watch for and } \\
\text { exploit windows of opportunity to advance } \\
\text { health promotion in the crowded health pol- } \\
\text { icy space } \\
\text { Can be used to identify the dynamic interactions } \\
\text { between policy problems, proposed solutions } \\
\text { and political will in any given situation }\end{array}$ \\
\hline
\end{tabular}

Norm life cycle framework (Finnemore and Sikkink, 1998)

ACF (Sabatier, 1988)

PET (Baumgartner and Jones, 1993)

'Special treatment' approach (Pedersen and Barlow, 2008) actors in a policy subsystem to advance issues that they seek to address. Once solutions are joined to problems, and both are joined to favourable political forces. An issue is recognized as a problem on the official (institutional) agenda and the public policy process starts addressing it. Policy windows may sometimes be opened by apparently unrelated external events, such as crises or the presence of 'policy entrepreneurs' both within and outside of government. At other times, these windows are opened by institutionalized events such as periodic elections or budget deadlines

Explains how new norms emerge and under which circumstances norm shift may appear. The norm life cycle argument focuses on change; it describes the process through which norms attain a wider reach and defines three stages through which a norm goes from its emergence until its general acceptance: emergence, cascade and internalization

Provides an overview of the entire policy process and explains what factors facilitate policy change over an extended time, modelling public policy as a translation of competing beliefs about contested issues. An advocacy coalition contains actors from a variety of positions (including elected and agency officials, interest group leaders, researchers) who share normative convictions and undertake coordinated activity over time. Advocacy coalitions learn from policy implementation, selectively interpreting information and using it to exercise power

Term originally used in evolutionary biology. Policymaking can appear stable for long periods. This theory aims to measure and explain how and why these long periods of policymaking stability and continuity are disrupted by short but intense periods of instability and change. Also includes the concepts of bounded rationality, selective attention and policy monopolies

The 'Special treatment' approach is informed by the perception that Aboriginal Australians unfairly receive preferential or special treatment. This framing denies the equity arguments that support the introduction of policy to improve the living conditions of Indigenous Australians.
Useful to assess how health promotion can enter crowded policy agendas and, over time, become an accepted policy priority

Assists in understanding the role of policy advocacy coalitions in strengthening or marginalizing health promotion as a priority in health policy

Highlights the importance of forming coalitions of advocates to advance arguments for health promotion policy

Explains that change happens unevenly and is more likely with a clear and consistent framing of health promotion messages

Enables health promoters to examine the impact of institutional racism on policy and practice and to understand why there is resistance to attempts to challenge racist systems 
Table 2: (Continued)

\begin{tabular}{|c|c|c|}
\hline $\begin{array}{l}\text { Theory-informed sense- } \\
\text { making tool }\end{array}$ & Key premise & $\begin{array}{l}\text { Application to understand and critique health } \\
\text { promotion policy and practice }\end{array}$ \\
\hline $\begin{array}{l}\text { Spectrum of Response } \\
\text { Framework (Sjoberg } \\
\text { and McDermott, 2016) }\end{array}$ & $\begin{array}{l}\text { The 'Spectrum of Response Framework' is intended } \\
\text { to aid the deconstruction of language to identify } \\
\text { aspects that are imbued with racialized power im- } \\
\text { balances. The aim is to challenge the perpetuation } \\
\text { of discriminatory ways of speaking and knowing, } \\
\text { particularly where discriminatory elements of } \\
\text { policy language and practice operate implicitly } \\
\text { and may be unexamined. Responses exhibited by } \\
\text { policy actors, manifest in policy framing and ac- } \\
\text { tivity. Responses range between (1) 'openness } \\
\text { and willingness to engage', (2) 'moved/uncertain', } \\
\text { (3) 'disturbed/flummoxed' and (4) 'hostile/reject- } \\
\text { ing', often evidenced by anger and dismissive be- } \\
\text { haviour, sometimes even overt racist commentary } \\
\text { or behaviour }\end{array}$ & \\
\hline
\end{tabular}

represented research engagement rather than more passive research transfer.

The benefits from the cross-disciplinary exchange of ideas emphasizes the value of forming and participating in networked, epistemic communities (Haas, 1992). Such networks involve knowledge-based experts from a diversity of fields, who each play a role in defining and problematizing issues, framing issues for collective debate, proposing strategies, evaluating likely or actual health impacts, and identifying salient points for negotiation and leverage (Haas, 1992). The action of such health policy networks can open up discussion about the role of policy in addressing the SDH, and mobilize evidence-based action that can accommodate political imperatives in order to produce policies that promote health and equity. The Workshop drew on such a network to encourage reflexivity among the researchers and public servants and also highlighted the value of drawing upon multiple theories to understand policy processes. Over time these reflections may contribute to more relevant and politically palatable policies which are able to advance the SDH and equity agendas. As suggested by Cairney, it is vital, however (Cairney, 2015), to ensure that actors within networked communities acknowledge the differences that may exist between academic and policy skills, and act deliberately to develop shared language and understandings. It is also imperative that academics facilitate meaningful engagement with policy makers by ensuring that they convey their ideas in a straightforward manner, thereby, making it easier for policy actors to use the ideas to inform practice (Cairney, 2015).

\section{How social and political science theory can inform health promotion}

The Workshop discussions confirmed that applying theory can be a powerful way to generate understanding about the reasons why disease prevention and health promotion policies still occupy a marginal position on policy agendas. The public servants who attended the Workshop emphasized the need for theory-driven findings to be produced in a way that is practically applicable, however. One way that this can be achieved is by making use of multiple theoretical frameworks and exploring the intersections among them rather than seeking a single theory that is adequate to understand complex, politically driven policy development and implementation systems.

Throughout the Workshop a range of theoretical frameworks and concepts were presented, some of which involved the hybridisation of theories and frameworks to expand understandings and to enable navigation of complex systems. Hybridizing multiple frameworks and theories assists in striking a balance between the conceptual clarity that can be derived from applying a particular framework, with the ability to capture and examine all aspects of multi-faceted, variable and contextually unique systems (Cairney, 2015; Howlett et al., 2015). The Workshop discussion confirmed Howlett et al.'s argument that this (Howlett et al., 2015) approach provides a means of weaving conceptual insights together to suit the particular policy system under investigation. Further, during the Workshop, it was agreed that policy research needs to be flexible in order to apply and test different theories in response to emergent findings. Theories that 
have been developed in relation to particular contexts and fields of study may not be more broadly applicable so researchers need to accommodate existing and emerging theories to maximize explanatory power. The contribution of de Leeuw provides a clear demonstration of this. Table 1 presents the theories and concepts discussed during the Workshop, which were identified as useful in understanding particular elements of policy processes. Table 2 expands on this, through demonstrating which aspects of health promotion policy and practice can be illuminated through the application of theory driven critique. The first column of Table 2 lists the collection of theories, concepts and models that presenters drew upon during the Workshop. Table 2 also shows the key learnings derived from the Workshop in terms of how the theories, concepts and models aid understanding of health promotion practice and policy.

Finally, a key theme of the Workshop was understanding the explanatory power of theory-driven critique. It was agreed that the application of theory strengthens the conclusions that can be reliably drawn from policy analysis, in particular by outlining the causal pathways between policy development and anticipated population health outcomes.

\section{CONCLUSION}

The Workshop provided a space in which critical analysis of the dynamics of contemporary Australian disease prevention and health promotion policy could occur. It allowed for an in-depth engagement between researchers and public servants that occurs all too rarely. The dilemmas of the conflicts between the demands of thoughtful and slow scholarship with the daily imperatives of the political expediency so often driving policy were evident throughout the discussions. The formation of engaged networks of researchers and public servants promises to increase the potential for deepened application of social and political theory to understanding public policy and its political, social and economic context. The discussions concluded that the application of theory promises to be most effective when it is multidisciplinary and blends and applies insights from a number of different theories. The Workshop deliberations led to recognition that as each stage of the policy cycle is greatly influenced by political considerations and is rarely, if ever, linear then an understanding of the complex systems, institutions and array of actors that govern policy is vital. As such, discussion during the workshop highlighted the importance of Cairney's observation that (Cairney, 2011) if only academics had told policy practitioners about complexity theory rather than the policy cycle, we would all be on the same page!

Recognition of such complexity, and non-linearity underlines the necessity of theories that advance understanding of how health issues rise to prominence, how government and non-government actors influence all stages of the policy cycle and how power operates to curtail policy options and promote the interests of the powerful. Our experiences from the ASSA Workshop indicate that more spaces that encourage constructive reflection by researchers and policy makers on the application of theories to policy will improve healthy public policy research, policy making, implementation and, ultimately, the health and wellbeing of communities.

\section{SUPPLEMENTARY MATERIAL}

Supplementary material is available at Health Promotion International online.

\section{ACKNOWLEDGEMENTS}

The authors thank Dr Kevin Buckett, Carmel Williams, Siobhan Harpur, Dr Anna Stevenson and Dr Anna Lane for their contributions during the Workshop.

\section{FUNDING}

This work was supported by workshop funding received from the Academy of Social Sciences Australia (ASSA).

\section{REFERENCES}

Aidt, T. S. and Dutta, J. (2007) Policy myopia and economic growth. European Journal of Political Economy, 23, 734-753.

Astbury, B. and Leeuw, F. (2010) Unpacking black boxes: mechanisms and theory building in evaluation. American Journal of Evaluation, 31, 363-381.

Bacchi, C. (2009) Analysing Policy: What's the Problem Represented to Be? Pearson Higher Education AU, Sydney.

Bacchi, C. (2016) Problematizations in health policy. SAGE Open, 6, 215824401665398.

Bacchi, C. L. (1999) Women, Policy and Politics: The Construction of Policy Problems, Sage, London.

Bacigalupe, A., Esnaola, S., Martín, U., and Zuazagoitia, J. (2010) Learning lessons from past mistakes: how can Health in All Policies fulfil its promises? Journal of Epidemiology and Community Health, 64, 504-505.

Baum, F. (2008) The New Public Health. Oxford University Press, Adelaide.

Baum, F., Lawless, A., Delany, T., Macdougall, C., Williams, C., Broderick, D. et al. (2014) Evaluation of Health in All Policies: concept, theory and application. Health Promotion International, 29, i130-i142. 
Baum F., Lawless A., MacDougall C., Delany T., McDermott D., Harris E. et al. (2015) New norms new policies: did the Adelaide Thinkers in Residence scheme encourage new thinking about promoting well-being and Health in All Policies? Social Science \& Medicine, 147, 1-9.

Baumgartner, F. R. (2013) Ideas and policy change. Governance, 26, 239-258.

Baumgartner, F. R. and Jones, B. D. (1993) Agendas and Instability in American Politics. University of Chicago Press, Chicago.

Baumgartner, F. R., Jones, B. D., and Mortensen, P. B. (2014) Punctuated equilibrium theory: explaining stability and change in public policymaking. Theories of the Policy Process, 59-103.

Breton, E. and de Leeuw, E. (2011) Theories of the policy process in health promotion research: a review. Health Promotion International, 26, 82-90.

Cairney, P. (2011) Understanding Public Policy: Theories and Issues. Palgrave Macmillan, Basingstoke.

Cairney, P. (2015) How can policy theory have an impact on policymaking? The role of theory-led academicpractitioner discussions. Teaching Public Administration, $33,22-39$.

Colebatch, H. (2010) Giving accounts of policy work. In Colebatch, H., Hoppe, R. and Noordegraaf, M. (eds), Working for Policy. Amsterdam University Press, Amsterdam, pp. 31-43.

Colebatch, H. K. (2005) Policy analysis, policy practice and political science. Australian Journal of Public Administration, $64,14-23$.

CSDH. (2008) Closing the gap in a generation: health equity through action on the social determinants of health. Final Report of the Commission on Social Determinants of Health. WHO, Geneva.

de Leeuw, E. and Clavier, C. (2011) Healthy public in all policies. Health Promotion International, 26, ii237-ii244.

de Leeuw, E., Clavier, C., and Breton, E. (2014a) Health policy-why research it and how: health political science. Health Research Policy and Systems, 12, 55.

de Leeuw, E., Green, G., Dyakova, M., Spanswick, L., and Palmer, N. (2015) European Healthy Cities evaluation: conceptual framework and methodology. Health Promotion International, 30, i8-i17.

de Leeuw, E., Hoeijmakers, M., and Peters, D. (2016) Juggling multiple networks in multiple streams. European Policy Analysis, 2, 196-217.

de Leeuw, E., Keizer, M., and Hoeijmakers, M. (2013) Health policy networks: connecting the disconnected. In Clavier, C. and de Leeuw, E. (eds), Health Promotion and the Policy Process, Oxford University Press, Oxford, pp. 154-173.

de Leeuw, E., Tsouros, A. D., Dyakova, M., and Green, G. (2014b) Healthy Cities, Promoting Health and Equity Evidence for Local Policy and Practice. WHO Regional Office for Europe, Copenhagen.

Delany, T., Lawless, A., Baum, F., Popay, J., Jones, L., McDermott, D. et al. (2015) Health in All Policies in South
Australia: what has supported early implementation? Health Promotion International, 31, 888-898.

Embrett, M. G. and Randall, G. E. (2014) Social determinants of health and health equity policy research: exploring the use, misuse, and nonuse of policy analysis theory. Social Science \& Medicine, 108, 147-155.

Exworthy, M., Blane, D., and Marmot, M. (2003) Tackling health inequalities in the United Kingdom: the progress and pitfalls of policy. Health Services Research, 38, 1905.

Finnemore, M. and Sikkink, K. (1998) International norm dynamics and political change. International Organization, 52, 887-917.

Fisher, M., Baum, F. E., MacDougall, C., Newman, L., and McDermott, D. (2016) To what extent do Australian health policy documents address social determinants of health and health equity? Journal of Social Policy, 45, 545-564.

Fisher, M., Baum, F. E., MacDougall, C., Newman, L., McDermott, D., and Phillips, C. (2017) Intersectoral action on SDH and equity in Australian health policy. Health Promotion International 32, 953-963.

Friel, S., Gleeson, D., Thow, A.-M., Labonte, R., Stuckler, D., Kay, A. et al. (2013) A new generation of trade policy: potential risks to diet-related health from the Trans Pacific Partnership agreement. Globalization and Health, 9, 46.

Government of South Australia. (2010) Implementing Health in All Policies: Adelaide 2010. Government of South Australia, Adelaide.

Greaves, L. J. and Bialystok, L. R. (2011) Health in All Policies-all talk and little action? Canadian Journal of Public Health, 102, 407-409.

Grimshaw, D. and Rubery, J. (2014) Neoliberalism 2.0: Crisis and austerity in the UK. In Lehndorff, S. (ed.), Divisive Integration: the Triumph of Failed Ideas in Europe. European Trade Union Institute, Brussels, pp. 41-58.

Haas, P. M. (1992) Introduction: epistemic communities and international policy coordination. International Organization, 46, 1-35.

Harris, P., Friel, S., and Wilson, A. (2015) 'Including health in systems responsible for urban planning': a realist policy analysis research programme. BMJ Open, 5, e008822.

Harris, P., Kent, J., Sainsbury, P., Marie-Thow, A., Baum, F., Friel, S. et al. (2017) Creating 'healthy built environment' legislation in Australia; a policy analysis. Health Promotion International, dax055-dax055.

Harris, P., Kent, J., Sainsbury, P., and Thow, A. M. (2016) Framing health for land-use planning legislation: a qualitative descriptive content analysis. Social Science \& Medicine, 148, 42-51.

Howlett, M., McConnell, A., and Perl, A. (2015) Weaving the fabric of public policies: comparing and integrating contemporary frameworks for the study of policy processes. Journal of Comparative Policy Analysis: Research and Practice, 1-17.

Howlett, M., McConnell, A., and Perl, A. (2016) Weaving the fabric of public policies: comparing and integrating contemporary frameworks for the study of policy processes. Journal 
of Comparative Policy Analysis: Research and Practice, 18, 273-289.

Howlett, M., Ramesh, M., and Perl, A. (1995) Studying Public Policy: Policy Cycles and Policy Subsystems. Cambridge University Press, Oxford.

Hunter, D. J., Popay, J., Tannahill, C., and Whitehead, M. (2010) Getting to grips with health inequalities at last? BMJ, 340, c684-c328.

Hunter, D. J., Popay, J., Tannahill, C., Whitehead, M., and Elson, T. (2009) Learning lessons from the past: shaping a different future. Marmot Review Working Committee 3. Cross-cutting sub-group report.

Jenkins-Smith, H. C., Nohrstedt, D., Weible, C. M., and Sabatier, P. A. (2014) The advocacy coalition framework: foundations, evolution, and ongoing research. In Sabatier, P. A. and Weible, C. M. (eds), Theories of the Policy Process, Westview Press, Boulder, pp. 183-223.

Kingdon, J. W. (2011) Agendas, Alternatives and Public Policies. Longman, Boston.

Kingdon, J. W. and Thurber, J. A. (1984) Agendas, Alternatives, and Public Policies. Little, Brown Boston, MA.

Lawless, A., Baum, F., Delany-Crowe, T., MacDougall, C., Williams, C., McDermott, D. R. et al. (2017) Developing a framework for a program theory-based approach to evaluating policy processes and outcomes: Health in All Policies in South Australia. International Journal of Health Policy and Management, 6, 1-12.

MacDougall, C. and Darbyshire, P. (2017) Collecting qualitative data with children. In Flick, U. (ed), The SAGE Handbook of Qualitative Data Collection. SAGE, Thousand Oaks CA, pp. 617-631.

Marmot, M., Friel, S., Bell, R., Houweling, T. A., Taylor S., o C $\&$ o. Health S. D. (2008) Closing the gap in a generation: health equity through action on the social determinants of health. The Lancet, 372, 1661-1669.

Miller, C. and Orchard, L. (2014) Australian Public Policy: Progressive Ideas in the Neoliberal Ascendency. Policy Press, Bristol, UK.

Ollila, E. (2011) Health in All Policies: from rhetoric to action. Scandinavian Journal of Public Health, 39, 11-18.

Osborne, K., Baum, F., and Brown, L. (2013) What works? A review of actions addressing the social and economic determinants of Indigenous health. Issues Paper no.7 produced for the Closing the Gap Clearinghouse. Australian Institute of Health and Welfare and Australian Institute of Family Studies, Canberra.

Pedersen, A. and Barlow, F. K. (2008) Theory to social action: a university-based strategy targeting prejudice against Aboriginal Australians. Australian Psychologist, 43, 148-159.

Popay, J., Whitehead, M., and Hunter, D. J. (2010) Injustice is killing people on a large scale-but what is to be done about it? Journal of Public Health, 32, 148-149.
Povlsen, L., Karlsson, L. E., Regber, S., Sandstig, G., and Fosse, E. (2014) Are equity aspects communicated in Nordic public health documents? Scandinavian Journal of Public Health, $42,235-241$.

Pressman, J. L. and Wildavsky, A. (1984) Implementation, 3r edition. University of California, Los Angeles, CA, p. 13.

Sabatier, P. A. (1988) An advocacy coalition framework of policy change and the role of policy-oriented learning therein. Policy Sciences, 21, 129-168.

Sjoberg, D. and McDermott, D. (2016) The deconstruction exercise: an assessment tool for enhancing critical thinking in cultural safety education. International Journal of Critical Indigenous Studies, 9, 28-48.

Smith, K. (2013) Beyond Evidence Based Policy in Public Health: The Interplay of Ideas. Springer, Basingstoke.

Ståhl, T., Wismar, M., Ollila, E., Lahtinen, E., and Leppo, K. (2006) Health in all policies. Prospects and Potentials. Finnish Ministry of Social Affairs and Health, Helsinki.

Steg, L., De Groot, J. I., Dreijerink, L., Abrahamse, W., and Siero, F. (2011) General antecedents of personal norms, policy acceptability, and intentions: the role of values, worldviews, and environmental concern. Society and Natural Resources, 24, 349-367.

Townsend, T. (2009) Third millennium leaders: thinking and acting both locally and globally. Leadership and Policy in Schools, 8, 355-379.

Weiss, C. H. (2000) Theory-based evaluation: theories of change for poverty reduction programs. In Feinstein, O. and Picciotto, R. (eds), Evaluation and Poverty Reduction: Proceedings from a World Bank Conference. The World Bank, Washington, pp. 103-114.

WHO (1997) Intersectoral Action for Health: A Cornerstone for Health for All in the Twenty First Century. Proceedings of an International Conference on Intersectoral Action for Health, Halifax, Canada.

WHO (2011) Rio Political Declaration on Social Determinants of Health. World Conference on Social Determinants of Health, Rio de Janeiro, Brazil.

WHO Task Force on Research Priorities for Equity in Health and The WHO Equity Team (2005) Priorities for research to take forward the health equity policy agenda. Bulletin of the World Health Organization, 83, 948-953.

World Health Organization (1978) Declaration of Alma Ata: report of the international conference on primary health care. Geneva.

World Health Organization (1986) Ottawa charter for health promotion. Geneva.

World Health Organisation (2010) The Adelaide Statement on Health in All Policies: moving towards a shared governance for health and well-being, http://www.who.int/social_deter minants/hiap_statement_who_sa_final.pdf (last acessed date 24 September 2012). 